\title{
Novel biotechnological approaches for monitoring and immunization against resistant to antibiotics Escherichia coli and other pathogenic bacteria
}

\author{
José E. Belizário ${ }^{1 *}$ (i) and Marcelo P. Sircili
}

\begin{abstract}
The application of next-generation molecular, biochemical and immunological methods for developing new vaccines, antimicrobial compounds, probiotics and prebiotics for zoonotic infection control has been fundamental to the understanding and preservation of the symbiotic relationship between animals and humans. With increasing rates of antibiotic use, resistant bacterial infections have become more difficult to diagnose, treat, and eradicate, thereby elevating the importance of surveillance and prevention programs. Effective surveillance relies on the availability of rapid, cost-effective methods to monitor pathogenic bacterial isolates. In this opinion article, we summarize the results of some research program initiatives for the improvement of live vaccines against avian enterotoxigenic Escherichia coli using virulence factor gene deletion and engineered vaccine vectors based on probiotics. We also describe methods for the detection of pathogenic bacterial strains in eco-environmental headspace and aerosols, as well as samples of animal and human breath, based on the composition of volatile organic compounds and fatty acid methyl esters. We explain how the introduction of these low-cost biotechnologies and protocols will provide the opportunity to enhance co-operation between networks of resistance surveillance programs and integrated routine workflows of veterinary and clinical public health microbiology laboratories.
\end{abstract}

Keywords: Bacterial vaccines, Microbiomes, Probiotics, Antibiotics, VOCs, And FAMEs

\section{Background}

In many South American countries, more than twothirds of all antimicrobials produced are administrated to animals, not human patients, mainly for growth promotion, treating animal disease and prophylaxis $[1,2]$. Indiscriminate use of antimicrobials may select for drugresistant pathogens as well as for mobile genetic elements (plasmids, bacteriophages) carrying antibiotic resistance genes (ARGs) to both human and nonhuman

\footnotetext{
* Correspondence: josebelizario223@gmail.com

'Department of Pharmacology, Institute of Biomedical Sciences, University of São Paulo, Av. Lineu Prestes, 1524, São Paulo, SP CEP 05508-900, Brazil Full list of author information is available at the end of the article
}

animal pathogens. In addition, antibiotic overuse contributes to the spread of antimicrobial-resistant organisms and increases the risk factor of infections and diseases in both animals and humans [3]. Bacteria commonly found in the poultry industry include Campylobacter spp., Staphylococcus spp., Salmonella spp., Clostridium perfringens type A, Enterococcus faecalis, and Escherichia coli $[4,5]$. Dietary supplementation with broad-spectrum antimicrobials such as bacitracin prevents the risk of necrotic enteritis caused by $C$. perfringens in broiler chickens. However, this provides the opportunity for increased antibiotic resistance. Transmission of antimicrobial-resistant bacteria can occur

(c) The Author(s). 2020 Open Access This article is licensed under a Creative Commons Attribution 4.0 International License, which permits use, sharing, adaptation, distribution and reproduction in any medium or format, as long as you give appropriate credit to the original author(s) and the source, provide a link to the Creative Commons licence, and indicate if changes were made. The images or other third party material in this article are included in the article's Creative Commons licence, unless indicated otherwise in a credit line to the material. If material is not included in the article's Creative Commons licence and your intended use is not permitted by statutory regulation or exceeds the permitted use, you will need to obtain permission directly from the copyright holder. To view a copy of this licence, visit http://creativecommons.org/licenses/by/4.0/ The Creative Commons Public Domain Dedication waiver (http://creativecommons.org/publicdomain/zero/1.0/) applies to the data made available in this article, unless otherwise stated in a credit line to the data. 
through direct contact, contaminated water, air, environment, and food [6-8]. The increase in the extendedspectrum cephalosporin resistance in Salmonella isolated from retail chicken is the most important public health problem in developing countries [6-8]. Furthermore, workers exposed to antibiotics and potential pathogens may disseminate antimicrobial-resistant bacteria in their community, contributing to evolutionary trajectories of evolving microbes and failures in antibiotic treatment outcomes [6-8]. Figure 1 illustrates a framework of biotechnological, antimicrobial stewardship and public health programs with the aim of reaching decisions regarding the adoption of these basic and applied technologies in study design and economic evaluations of the global challenges in the rational use of antibiotics in human beings and animals.

Animal fecal microflora harbor a vast reservoir of antibiotic-resistance genes, which are predominantly acquired by human commensal and pathogenic bacteria $[10,11]$. The abuse and unreasonable utilization of antimicrobials for clinical, agricultural and pharmaceutical purposes can lead to a selective pressure in metabolic and oxidative biochemical processes for DNA mutation $[1,12]$. Sublethal bactericide pressure can increase mutagenesis in hypermutator bacterial strains and the acquisition of resistance genes [12]. Several antibiotics have been used in feed or water at sub-therapeutic levels for growth promotion for over 50 years [13, 14]. Subtherapeutic in-feed antibiotics such as erythromycin, penicillin, gentamicin, neomycin, tetracyclines, bacitracin methylene disalicylate and virginiamycin (streptogramin $\mathrm{A}$ and B) are commonly used for growth promotion or prophylaxis in poultry production [15]. Moreover, sublethal doses of bactericide antibiotics promote the specialization of various different bacteria genotypes within the whole heterogeneous bacterial population. For example, sublethal doses of norfloxacin over 10 days greatly increase resistant isolates from the E. coli population, which release indole, a signaling molecule that protects less resistant isolates. The rise of extendedspectrum beta-lactamase (ESBL)-producing E. coli in food-producing animals poses significant challenges to clinicians and negatively impacts patient healthcare in hospitals $[8,16]$. Studies of fecal resistome indicated that diverse genera of Enterobacteriaceae, including $E$. coli, Klebsiella, Shigella, and Salmonella have acquired different antibiotic resistance genes [17, 18]. Remarkably, E. coli strains are the predominant (83\%) bacterial host of genes for resistance to tetracycline, aminoglycoside, macrolide, lincosamide, streptogramin, $\beta$-lactam and sulfonamides $[8,16]$.

Airborne cross-transmission of pathogenic bacteria between animals and workers in swine and dairy facilities has been well characterized through surveillance programs [19]. These studies have reinforced the necessity for implementation of surveillance programs to detect the spread of zoonotic diseases between animals and the population [19]. Poultry workers in general acquire

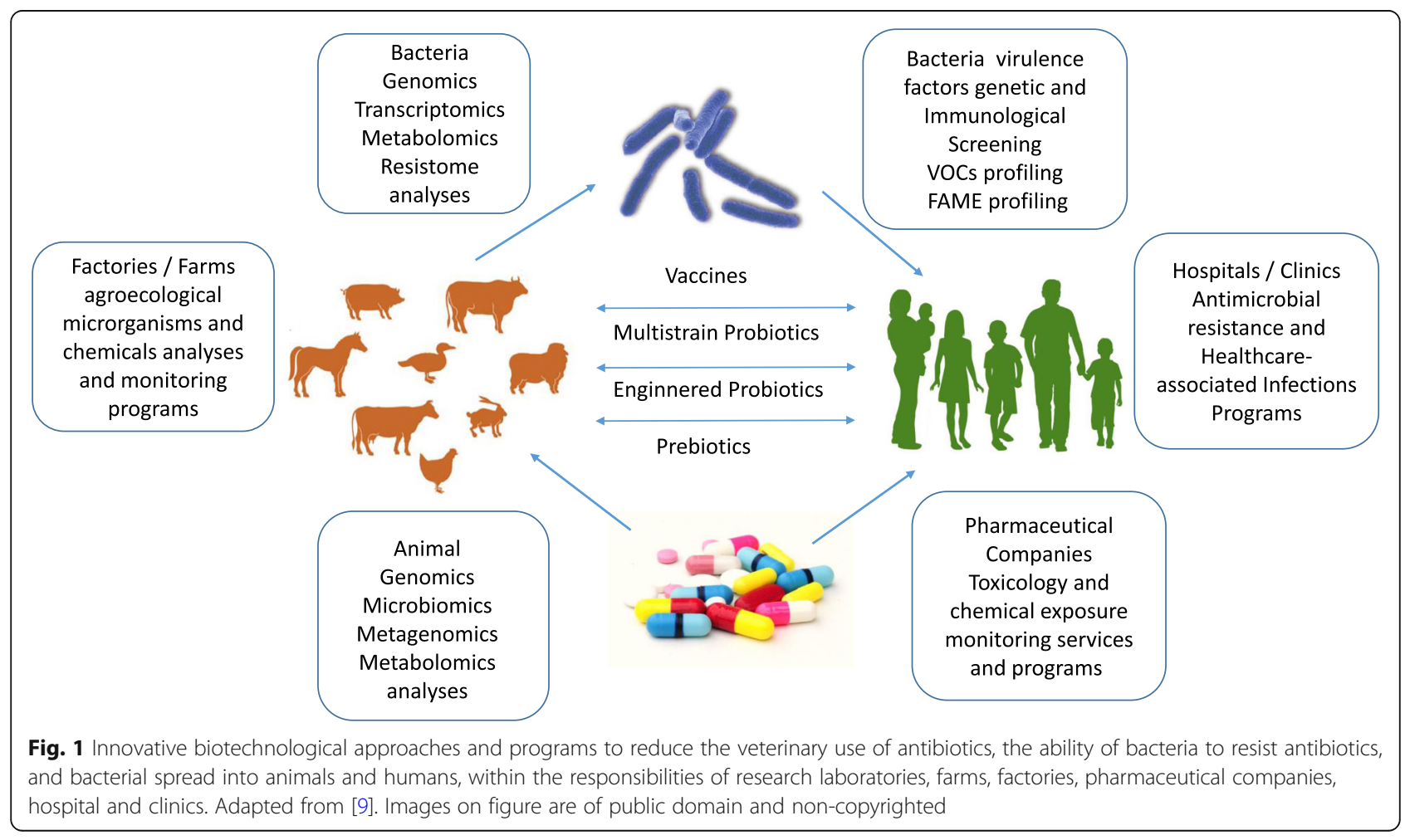


Campylobacter through orally transmitted water droplets $[19,20]$. However, the presence of antibioticresistant bacteria in biological aerosols is largely not understood. Therefore, innovative approaches are necessary to monitor and collect specific solid and organic volatile compounds that are produced and released by large animal feeding and factory facilities.

Poultry facilities are associated with a high production of dust, gases, and odors [4, 20]. In poultry bioaerosols, bacteria exist suspended freely in the air as well as attached to dust particles $[4,20]$. The presence of antimicrobial genes in poultry bioaerosols suggests that poultry farmers may be potential nasal carriers of antimicrobial-resistant bacteria, which could potentially be transmitted to susceptible persons [14]. Swine workers are also nasal carriers of resistant bacterial species [14] Pathogenic bacteria carrying tetracyclineresistance genes were detected in bioaerosols from swine confinement buildings and nasal swabs of swine workers [21]. Finally, respiratory pathogens such as Haemophilus influenzae, Streptococcus pneumoniae, and Moraxella catarrhalis are commonly detected in blood, cerebrospinal fluid, higher and lower respiratory tract, urine, and wound or pus of farm animals and humans. Substantial investments are needed to develop the innovative vaccines for these new targets at the commercial scale. In this opinion article, we will update specifically on potential vaccines in development against avian pathogenic E. coli strains and novel engineered vaccine probiotics based on Lactobacillus spp. and yeasts. In the second part, we will describe the technical and biotechnological discoveries that are being implemented for early identification of presence/absence of pathogenic bacterial strains, including those with acquired antimicrobial resistance based on the composition of volatile organic compounds (VOCs) and volatile fatty acids (FAMEs).

\section{Antibiotic growth-promoting effects}

In-feed antibiotic supplementation exerts growthpromoting effects in farm animals, through a yet unclear mechanism [22]. Early studies demonstrated that the use of antibiotics promotes the suppression of the number and diversity of the normal gut bacterial flora and the production of certain microbial metabolites while increasing the concentration of critical nutrients [23] The large-scale systematic analysis of farm animal microbiomes has recently emerged. There are few studies addressing the long-term dynamics of the intestinal microbiota in relation to changes in energy absorption and/or food intake under antibioticinduced growth treatment. Chickens fed with virginiamycin- and bacitracin-supplemented diets had reduced microbial diversity, with an increase in Enterococcus and Lactobacillus spp. and a decrease of L. salivarius [24]. The development of new generation genomic and metabolomic approaches has allowed analyses of the differences in intestinal microbiota composition and the amino acids, vitamins and metabolites they produce under diverse diets and antibiotic intervention [25]. Based on a metabolomics approach, Gadde and colleagues in a recent study proposed a mechanism by which dietary antibiotics may exert enhanced growth promotion in broiler chickens [24]. They showed that antibiotic treatment alters the host intestinal anti-inflammatory response in parallel with changes in the structure and diversity of the gut microbial community [24]. Antibiotic supplementation with bacitracin increased the production of polyunsaturated fatty acid (PUFA) levels in the chicken intestine. Fatty acids are incorporated into the membranes of leukocytes and serve as substrates for production of bioactive lipid mediators. Three biosynthetic routes working independently or in concert produce prostaglandins, leukotrienes, lipoxins and resolvins, which are well known mediators of pro- and anti-inflammatory effects during the early and late phases of an inflammation. Dietary supplementation with omega-3 PUFAs such as eicosapentaenoic acid (EPA) and docosahexaenoic acid (DHA) are known to reduce inflammatory reactions [26]. Considering that the antibiotics are given in absence of inflammation, studies have been carried out to identify which are the cells and mediators responsible for antibiotic effects. Previous studies have identified that neutrophils are targeted and killed by apoptosis after macrolide tilmicosin treatment [27]. Along inflammatory response and diverse disease setting, lipoxins act as potent anti-inflammatory mediators and promote neutrophil killing in the resolution phase of an inflammation [26]. Do these local lipid mediators serve as effectors of antibiotics? In this way, it is quite possible that resolvins and protectins derived from DHA could also promote the clearance of neutrophils from mucosal surfaces [26]. This remains to be further investigated.

Synthetic microbiomes and engineered vaccine probiotics Dysbiosis of healthy gut microbiota plays a critical role in the dysregulation of microbial ecology that favors colonization of pathogenic bacterial strains and diseases [28]. The literature is replete with studies that characterize the structure and diversity of the gut microbiome, through sequencing the 16S RNA gene, and the correlation with different nutritional states, including obesity and malnutrition, as well as many metabolic and inflammatory disorders [29]. The current hypothesis is that the size of or shift in the Prevotella enterotype/Bacteroides enterotype ratio determines the variations in the production of short chain fatty acids (SCFAs) acetate, propionate, butyrate and lactate [29-32]. These molecules are critical metabolic substrates for gluconeogenesis and lipogenesis that drive obesity [32]. SCFAs, particularly, propionic and butyric acids, may directly 
prevent the low-grade inflammatory response observed in some obese populations [32, 33]. Bacteriotherapy or fecal microbiota transplantation have been in clinical practice over centuries, in particular in the treatment of refractory cases of Clostridium difficile colorectal infection after antibiotic therapy [28]. In this context, competitive exclusion (CE) products derived from healthy specific-pathogen-free chickens and administered by crop gavage have been used as feed supplements in broiler chickens [34-36]. This type of bacteriotherapy effectively increases the resistance and protects chickens from bacterial infections, notably salmonellosis [34]. Freeze-dried $\mathrm{CE}$ preparations are manufactured and commercialized in many countries [37]. Simple fecal transplantation or microbiota transfer can reproduce obesity or leanness in animal models [29, 30]. Nonetheless, since host-associated microbes perform several important functions, in particular metabolic and immunological functions, the question is: How many strains or species belonging to Firmicutes, Bacteroidetes and Actinobacteria phyla are needed for a minimal microbiome that could exert all microbial functions? Synthetic microbial communities with specific desired metagenomes and function can be designed and manufactured reproducibly [38]. For instance, bacterial species or consortia that are associated with resistance to infection could be designed. Therefore, there is great expectation of the development and application of future engineered synthetic microbiomes in which a personalized (or animalized) diet will improve healthy animal growth.

The World Health Organization (WHO) has defined probiotics as live organisms that, when administered in adequate amounts, confer a health benefit to the host. Probiotics are, in general, members of the microbiota. Extensive basic and clinical studies with lactic acid bacteria strains such as Bifidobacteria spp., Bacteroides and Akkermansia spp. have provided strong evidence of their health benefits. This is achieved through multiple mechanisms and effector molecules [32, 39, 40]. In-feed supplementation with Bacillus, Bifidobacterium, Enterococcus, Lactobacillus, Streptococcus, Lactococcus spp. and Yeast Saccharomyces have been given as probiotics to inhibit infection of enteric pathogens and mitigate antibiotic-associated diarrhea [41-43]. Recently, probiotics based on L. lactis and Lactobacillus spp. have been explored as delivery vectors of therapeutics and antigens expressed by virus and bacteria [44]. Novel engineered probiotics based on yeast strains, mainly Saccharomyces boulardii, have been constructed to secrete multispecific and single-domain antibodies directly targeting bacterial virulence factors, in particular, enterotoxins [45]. Specifically, S. boulardii was engineered to express one or more antigens aiming to improve the immune response to C. difficile and Campylobacter jejuni infection [46]. Furthermore, these probiotic strains can be engineered, or reprogrammed, for heterologous gene expression of amino acids, peptides and antimicrobial compounds to combat multiple pathogens [38, 43, 44] Yet, fundamental questions remain: Does the make-up of the gut microbiome impact the development of body carcass from the perspective of quantitative bioenergetics? How might we monitor and manipulate the gut microbiome to optimize the complex diet-microbiome relationship and positively impact the host? These are some questions to be answered.

\section{Chicken E. coli vaccines}

Enterotoxigenic E. coli (ETEC) infection is globally the most common cause of serious diarrheal illness [47]. Active vaccination (long lasting) and passive immunization with antibodies (short-lived) are the most appropriate immunological methods to prevent diseases caused by bacterial pathogens. Live vaccines consisting of attenuated strains of key serotypes is an alternative way to avoid the continued use of antibiotics in veterinary medicine [48]. In Brazil, the world's largest exporter of chicken meat, Enterobacteriaceae species are responsible for more than $45 \%$ of condemned poultry carcasses [49]. $E$. coli is considered a major source of the spread of antimicrobial resistance to other bacteria, which are mainly mediated by exchange of genes, integrons, transposons, and plasmids $[47,48]$. Avian E. coli strains are clearly differentiated with respect to phylogenetic relationships, common virulence factors and pathogenicity to animals and humans [50-52]. Single isolates within species from different geographical areas vary profoundly in terms of virulence factor traits and antibiotic-resistance genes. More knowledge of the molecular basis of this variability will help in the design of new rational approaches to monitoring pathogenicity and immunogenicity of new bacterial mutants.

Many ETEC strains colonize the gastrointestinal tract of birds and mammals where they live in a commensal relationship [47, 48]. The avian pathogenic E. coli (APEC) strains cause systemic septic colibacillosis, which is characterized by bloodstream invasion resulting in massive lesions in multiple internal organs and sudden death of birds. Extra-intestinal pathogenic E. coli (ExPEC) strains are commonly associated with nosocomial and community infections in humans and animals [49-53]. A larger number of ExPEC isolates from humans and animals of have been characterized based on their origins as follows: uropathogenic $E$. coli (UPEC), neonatal meningitis $E$. coli (NMEC) sepsis-associated $E$. coli (SEPEC), and avian pathogenic E. coli (APEC) [47, 48, 54]. It is interesting that ExPEC isolates from humans and chickens have similar virulence traits and 
common genes [47, 48, 54, 55]. A conserved set of 13 virulence-associated genes identified APEC isolates. The most studied are fim $C$, astA, papC, tsh, fyuA, irp2, iucD, iss, hlyE, eaeA, vat, colV, and stx2f. This set of genes has been used to confirm genotypically and phenotypically the relationships among pathogenic APEC isolates [56, 57]. The virulence genes for adhesins fimH (Type 1 fimbriae) and $t s h$ (temperature-sensitive hemagglutinin), protectin iss (increased serum survival) and the iron acquisition system genes (iron-scavenging systems) are examples of genes that convert intestinal commensal into pathogenic E. coli (APEC). Many studies have supported the role of APECs as zoonotic and foodborne pathogens $[50,54]$. Currently serotypes O1:K1, O2:K1 and O78:K80 are recognized as the most prevalent serotypes among more than 20 APEC subtypes identified in animal studies. However, despite the huge importance of APECs for bird health there are few studies searching for genes evolved in recombination and positive selection as well as specific virulence factors associated with traits and phenotypes [49-51]. More importantly, most the time these pathogenic strains are carrying plasmids that disseminate resistance to ampicillin, tetracycline, gentamicin, neomycin, sulfa trimethoprim, enrofloxacin and norfloxacin [5, 58]. ExPEC-commensal $E$. coli strains harboring multidrug resistance (MDR) have also been isolated in different poultry farms [52]. Therefore, continuous monitoring of bacterial resistance genes among E. coli ExPEC and APEC isolates from chicken meat products will aid the development of surveillance programs and new scientific strategies for food safety.

A series of studies was conducted by Dr. Wanderley Silveira's group (UNICAMP, Campinas, Brazil) to identify molecularly the APEC strain SEPT362, serotype OR: $\mathrm{H} 10$, which was isolated from liver of a laying hen presenting clinical signs of septicemia [59-61]. Overall, the results suggested that the pathogenicity of APEC strain SEPT362 and its biological characteristics are determined by a set of genes controlling the type VI secretion system (T6SS). The authors generated three E. coli APEC mutant strains deficient in $h c p, c l p V$ and icmF genes of the T6SS and investigated their function in the SEPT361 E. coli-induced lethality in chicks [59-61]. Chicken infected with $E$. coli deficient in $h c p$ and $c l p V$ genes had a survival rate of $93 \%$ on the first day, $68 \%$ on the third day, and $50 \%$ on the sixth day after infection. Vaccination with $E$. coli deficient in $c l p V$ gene only significantly increased survival rates of chicken over 30 days of experimentation. The pathogenicity was not significantly decreased with $E$. coli mutants of $i c m F$ gene. On the other hand, it was observed that $i c m F$ gene E. coli mutant reduced intracellular viability of $E$. coli in infected macrophages. Furthermore, all E. coli mutants showed a reduced biofilm formation capacity as compared to wild-type SEPT362 strain. Overall, the results suggest that E. coli SEPT362 deficient in $h c p, c l p V$ and $i c m F$ genes have enhanced safety, stability and the potential capacity as live or attenuated vaccine for future experimental study aimed at chicken vaccination against $E$. coli. Various attempts have been made to develop an effective vaccine against the respiratory form of APEC diseases in poultry [62, 63]. The enzyme 5-enolpyruvylshikimate-3phosphate synthase (EPSPS), also designated as AroA, participates in the biosynthesis of aromatic amino acids. A live vaccine based on an E. coli mutant strain with aroA deleted has been used as a spray vaccine. This live-attenuated APEC O78 $\triangle$ aroA vaccine (Poulvac ${ }^{\ominus} E$. coli) protected the manifestation of colibacillosis in chickens infected with homologous and heterologous APEC strains [64]. However, another study demonstrated that this vaccine was incapable, by itself, of inducing humoral immunity in turkeys. An efficient cellular immune response was only observed when the vaccine was administrated with strong coadjuvants containing CpG nucleotides [65]. The quorumsensing system (QS) plays important roles in the production of bacterial toxins, biofilm formation, and pathogenicity of APECs [66]. The luxS is a gene that codes for a Sribosylhomocysteine lyase that catalyzes the substrates for production of the autoinducer 2 (AI-2), a furanosyl borate that coordinate AI-2 QS system involved in the densitydependent processes in Gram negative and positive bacteria. A live-attenuated APEC strain deficient in both luxS gene and aro $A$ gene, which participates in the biosynthesis of aromatic amino acids, has been evaluated as potential vaccine candidate [67]. This double-mutant strain attenuated APEC virulence by more than six-fold as compared to the single-mutant strain DE17 [67]. Together, the results of these studies suggest that the virulence deletion approach is a worthy strategy to produce safe live and attenuated vaccines to prevent avian colibacillosis. More importantly, these studies predict that vaccination is an appropriate method for reducing the rise and spread of resistant $E$. coli APEC strains within animals and the community.

\section{VOCs}

DNA/RNA/protein high-throughput sequencing and/or structural determination methods are powerful tools to give a deeper qualitative and quantitative insight into bacterial species and their resistomes [10-12]. Simple and cost-efficient methods for collecting exhaled breath and extracting DNA, proteins, peptides, metabolites and VOCs are in development for bacterial species and genera identification. Bacteria have distinct metabolic pathways compared to human cells; thus, their presence can be characterized by odor and/or release of inert VOCs [68]. Over 1000 VOCs emitted by bacterial and fungal strains categorized by classes and chemical structures have been cataloged [69]. The gastrointestinal microbiota produces a 
wide range of sulfur-containing gaseous substances, including hydrogen sulfide $\left(\mathrm{H}_{2} \mathrm{~S}\right)$, which serves as a substrate for methane synthesis, methyl mercaptan, dimethyl sulfide, dimethyl disulfide and trisulfide. All these compounds are toxic and induce inflammation when in high concentration. The end products of anaerobic bacteria fermentation of oligosaccharides include succinate and a mixture of volatile fatty acids, mainly acetate, propionate, cis-2-methylcrotonate, 2methylbutyrate and 2-methylvalerate, SCFAs, as well as alcohols, hydrocarbons, aldehydes, ketones and sulfated organic compounds [68, 70-72]. Many of these organic compounds can be detected in expelled air, feces and urine and explored for confirmation of pathogenic infection [68, 70-72]. Indole has been used clinically as a predictive biomarker of $E$. coli biofilm. Butyric acid is a biomarker for some Clostridium species, acetaldehyde for some Staphylococcus species, and long chain alcohols are important biomarkers for the detection of Salmonella. VOCs can discriminate pathogen interactions commonly observed in human clinical infections. For example, high levels of 2-methylbutylacetate and methyl 2-methylbutyrate, two known antimicrobial VOCs, were found only in a co-culture of E. cloacae and P. aeruginosa [73]. A systematic review of the literature identified 161 VOCs emitted during sepsis in children [68]. The author identified VOC signatures that allowed prediction of the presence of the Gram-positive bacteria Staphylococcus aureus, Streptococcus pneumonaie and Enterococcus fecallis, and the Gram-negative bacteria E. coli, Pseudomonas aeruginosa and Klebsiella pneumoniae [68]. Palma and colleagues, using a machine-learning algorithm, identified a group of 18 VOCs that could predict with accuracy and precision 11 species of bacteria, protozoa and fungi [74]. The growing international community of breath VOC researchers is conducting standardized large-scale studies to catalog endogenously derived volatile compounds originating from pathogens in culture and released in exhaled human breath, skin, urine, feces, and flatulence in healthy and diseased people as well as from plants, foods, and soil microorganisms $[68,71]$. The mVOC database (http://bioinformatics.charite.de/mvoc) is one user-friendly platform for VOC-based retrieval. Such databases will help establish a powerful resource for investigation of the modulatory effects of VOCs in bacterial growth control and resistance to antibiotics.

Animal feeding operations produce a larger number of gaseous chemical compounds [75]. More than 100 VOCs were identified in the indoor and outdoor air, stable and road dust and soil samples from pig and cattle farms [75]. Acetic acid, butanoic acid, p-cresol, propanoic acid, pentanoic acids, phenol and hexanal were found in the indoor air of pig farms, and acetic acid, butanoic acid, propanoic acids, p-cresol, phenol and methyl esters of carboxylic acids in the indoor air of cattle farms [75]. Various chemical substances were identified using gas chromatographic analysis of VOCs captured by evacuated canisters and sorbent tubes distributed at critical points of the installations. Besides gas chromatography methods, various automated devices for the detection of VOCs have been developed using a wider array of sensor heads (eNose) and detection systems [76-78]. These specific sensor types can offer simple solutions for specific criteria in terms of selective detection of target VOCs in field applications. The speciation and levels of VOCs released in animal facilities and production stations include compounds formed by biotic and abiotic stress. Thus, there is opportunity for development and application of a range of biotechnological and chemical techniques to access the volatility and reactivity of VOCs with respect to opportunistic pathogens such as Micrococcus, Bacteroides, Chryseobacterium, Pseudomonas, and Acinetobacter and parasites specifically found in domestic animals. The creation of databases of microorganism-specific VOC signatures using such methodologies has great potential for tracking the presence and spread of antibiotic-resistant species dispersed through bioaerosols.

\section{FAMEs}

The fatty acid composition of bacterial species is genetically conserved [79]. When esterified by an alkali-catalyzed reaction with methanol, the fatty acids become volatile enough for analysis by gas chromatography [80]. The analysis of the volatile fatty acids (VFAs), in their free acid form, or as fatty acid methyl esters (FAMEs) can be used to predict the presence of aerobic and anaerobic bacteria [80-82]. Gas chromatography/mass spectrometry (GC/MS) analysis of fatty acids between 9 and 20 carbons in length (microbial fingerprinting) is a conventional method to characterize genera and species of bacteria, especially non-fermentative Gramnegative organisms $[82,83]$. The system for naming and counting carbons is from the carboxyl end (omega end). For example, terminally branched saturated FAMEs indicate the presence of Gram-positive bacteria and monounsaturated or hydroxylated FAMEs Gram-negative bacteria. Normally, polyunsaturated FAMEs are rarely encountered in bacteria. Over 1500 bacterial species have been identified based on their unique fatty acid profiles on commercial identification systems such as the Sherlock Microbial Identification System [80, 84]. In a recent publication, Roth and colleagues developed a GC method to characterize dental bacterial plaque via FAME profiling [85]. They successfully identified saturated and monoenoic FAMEs in the biofilm cultivated in vitro from 10 donors [85]. A machine-learning bioinformatics approach called phylogenetic learning has been used for FAME-based bacterial species classification [86]. FAME database [http://www.fame-bank.net] is an open platform that displays a taxonomic framework 
classifier based on FAME composition and bacterial $16 \mathrm{~S}$ rRNA gene sequences [86]. Thus, we expect that the expansion of VOCs and FAMEs chemical signatures will improve our understanding of the role of participating bacteria from different genera and species as well as strains of the same species. These methods can potentially impact the speed and accuracy by which bacterial antibiotic-resistant species are identified and correctly treated.

\section{Conclusions and outlook}

Global environmental changes and ecosystem impairments have contributed to the dissemination of bacterial pathogens from animals to humans and vice-versa. Despite progress in some countries, effective and coordinated strategies, such as antimicrobial stewardship and One Health strategy, for the containment of misuse of antimicrobials and the spread of antibiotic-resistant microorganisms have not been globally implemented [87]. The European Union has banned the non-therapeutic feeding of a number of antibiotics of human importance to farm animals. However, Europeans consume antibiotic-treated vegetables and meat products from countries that allow the use of antibiotics. Therefore, a global solution to these problems depends on the development of novel innovative biotechnologies to enhance co-operation with and between networks of public bacterial resistance surveillance programs. We need to be prudent and maintain rational prescribing programs in pro-growth, prophylactic and therapeutic use of veterinary antibiotics to eliminate existing resistant bacterial strains from a population and new ones that may arise in the future [88, 89]. More attention should be done in providing best practices for the prescription of antibiotics to farmers and veterinary personnel with confirmed presence of both animal and nosocomial antimicrobial resistant pathogens. In this way, we need to improve science through robust investments in the research, development, and implementation of stewardship programs in all outpatients and inpatients healthcare settings.

The next generation of live bacterial strains and engineered probiotics based on lactic acid bacteria and yeast as vaccine delivery vectors offer many attractive advantages over traditional recombinant vaccines. Rapid diagnostic methods for bacterial infections and airborne disease outbreaks in farm animals and communities are constant challenges faced by hospitals and health institutions in developing countries. Antibiotic stewardship programs are a key component in preventing the spread of antibiotic resistance in all healthcare facilities and across the world. Non-invasive and fast diagnostic tools based on breath biopsy hold great promise in identifying animal and human pathogens. The implementation and use of chromatography and mass spectrometry methods and chemical sensors in the clinical laboratory for determination of VOCs and FAMEs have immense potential in the development of biomarkers for the early diagnosis of infectious diseases. Finally, the application of these innovative methods will provide quantitative insights into the contribution of microbiota to farm animal growth and enable future studies on the interacting roles of diet and gut microbiome on animal physiology and health.

\section{Acknowledgements \\ The authors would like to thank for assistance and comments of lab students and collaborators from University of Sao Paulo and Butantan Institute. A special thanks to Dr. Wanderley Silveira (UNICAMP, Campinas, Brazil) for pioneering research on vaccine candidates to avian E. coli ExPEC strains and to BMC reviewer(s) for their contribution.}

\section{Authors' contributions}

JEB and MPS participated in designing the study and in the critical review of the content of selected manuscripts cited here. The authors have approved the final version of the manuscript and are responsible for all aspects, ensuring its accuracy and completeness.

\section{Funding}

The authors were supported by Conselho Nacional de Desenvolvimento Científico e Tecnológico (CNPq, proc. 486048/2011, proc. 312206/2016-0), and Fundação de Amparo a Pesquisa do Estado de São Paulo (proc 2012/ 02497-7, proc. 2014/20847-0, proc. 2010/06707-0, proc. 2008/05519-6). The funders played no role in the design as well as conclusion of the study.

Availability of data and materials

Data sharing is not applicable to this kind of article.

Ethics approval and consent to participate

Not Applicable.

Consent for publication

Not Applicable.

Competing interests

The authors declare no conflicts of interest.

\section{Author details}

${ }^{1}$ Department of Pharmacology, Institute of Biomedical Sciences, University of São Paulo, Av. Lineu Prestes, 1524, São Paulo, SP CEP 05508-900, Brazil.

${ }^{2}$ Laboratory of Genetics, Butantan Institute, Av. Vital Brazil, 1500, São Paulo, SP CEP 05503-900, Brazil.

Received: 1 April 2019 Accepted: 21 October 2020

Published online: 02 November 2020

References

1. Anderson IA, Hughes D. Microbiological effects of sublethal levels of antibiotics. Nat Rev Microbiol. 2014;12(7):465-78. https://doi.org/10.1038/ nrmicro3270.

2. Van den Bogaard AE, Stobberingh EE. Epidemiology of resistance to antibiotics: links between animals and humans. Int J Antimicrob Agents. 2000;14:327-35. https://doi.org/10.1093/jac/49.3.497.

3. Melo LC, Oresco C, Leigue L, Netto HM, Melville PA, Benites NR, et al. Prevalence and molecular features of ESBL/pAmpC-producing Enterobacteriaceae in healthy and diseased companion animals in Brazil. Vet Microbiol. 2018;221:59-66. https://doi.org/10.1016/j.vetmic.2018.05.017.

4. Just N, Kirychuk S, Gilbert Y, Létourneau V, Veillette M, Singh B, et al. Bacterial diversity characterization of bioaerosols from cage-housed and floor housed poultry operations. Environ Res. 2011;111:492-8. https://doi. org/10.1016/j.envres.2011.01.009.

5. Pedroso AA, Hurley-Bacon AL, Zedek AS, Kwan TW, Jordan APO, Avellaneda $G$, et al. Can probiotics improve the environmental microbiome and Resistome of commercial poultry production? Int J Environ Res Public Health. 2013;10(10):4534-59. https://doi.org/10.3390/ijerph10104534. 
6. Brooks JP, McLaughlin MR, Scheffler B. Microbial and antibiotic resistant constituents associated with biological aerosols and poultry litter within a commercial poultry house. Sci Total Environ. 2007;408:4770-7. https://doi. org/10.1016/j.scitotenv.2010.06.038.

7. Folster JP, Pecic G, Singh A, Duval B, Rickert R, Ayers S, et al. Characterization of extended-spectrum cephalosporin-resistant salmonella enterica serovar Heidelberg isolated from food animals, retail meat, and humans in the United States 2009. Foodborne Pathog Dis. 2012;9(7):638-45. https://doi.org/10.1089/fpd.2012.1130.

8. Monte DF, Mem A, Fernandes MR, Cerdeira L, Esposito F, Galvao J, et al. Chicken meat as a reservoir of colistin-resistant Escherichia coli strains carrying mcr-1 genes in South America. Antimicrob Ag Chemother. 2017; 61(5):e02718-6. https://doi.org/10.1128/AAC.02718-16.

9. Harbarth S, Balkhy HH, Goossens H, Jarlier V, Kluytmans J, Laxminarayan R, et al. Pittet $D$ and for the world healthcare-associated infections resistance forum participants. Antimicrob Resist Infect Control. 2015;4:49. https://doi. org/10.1186/s13756-015-0091-2.

10. Galán J-C, González-Candelas F, Rolain J-M, Cantón R. Antibiotics as selectors and accelerators of diversity in the mechanisms of resistance: from the resistome to genetic plasticity in the $\beta$-lactamases world. Front Microbiol. 2013;4:9. https://doi.org/10.3389/fmicb.2013.00009.

11. Yarygin KS, Kovarsky BA, Bibikova TS, Melnikov DS, Tyakht AV, Alexeev DG. ResistoMap - online visualization of human gut microbiota antibiotic resistome. Bioinformatics. 2017;33(14):2205-6. https://doi.org/10.1093/ bioinformatics/btx134.

12. Alekshun MN, Levy SB. Molecular mechanisms of antibacterial multidrug resistance. Cell. 2007;128(6):1037-50. https://doi.org/10.1016/j.cell.2007.03. 004.

13. Kohanski MA, DePristo MA, Collins JJ. Sublethal antibiotic treatment leads to multidrug resistance via radical-induced mutagenesis. Cell. 2010;37(3):31120. https://doi.org/10.1016/j.molcel.2010.01.003.

14. Zhu YG, Johnson TA, Su JQ, Qiao M, Guo GX, Stedtfeld RD, et al. Diverse and abundant antibiotic resistance genes in Chinese swine farms. Proc Natl Acad Sci U S A. 2013;110:3435-40. https://doi.org/10.1073/pnas.1222743110.

15. Thibodeau A, Quessy S, Guévremont E, Houde A, Topp E, Diarra MS, et al. Antibiotic resistance in Escherichia colli and enterococcus spp. isolates from commercial broiler chickens receiving growth-promoting doses of bacitracin or virginiamycin. Can J Vet Res. 2008;72(2):129-36 PMID: 18505201.

16. Nordmann P, Poirel L. The difficult-to-control spread of carbapenemase producers among Enterobacteriaceae worldwide. Clin Microbiol Infect. 2014; 20(9):821-30. https://doi.org/10.1111/1469-0691.12719.

17. Mohd-Shaufi MA, Sieo CC, Chong CW, Gan HM, Ho YW. Deciphering chicken gut microbial dynamics based on high-throughput 165 rRNA metagenomics analyses. Gut Pathog. 2015;7:4. https://doi.org/10.1186/ s13099-015-0051-7.

18. Mathers AJ, Peirano G, Pitout JDD. The role of epidemic resistance plasmids and international high-risk clones in the spread of multidrug resistant Enterobacteriaceae. Clin Microbiol Ver. 2015;28(3):565-91. https://doi.org/10. 1128/CMR.00116-14.

19. Feld L, Bay $H$, Angen $\varnothing$, Larsen AR, Madsen AM. Survival of LA-MRSA in dust from swine farms. Ann Work Expo Health. 2018;62(2):147-56. https://doi.org/ 10.1093/annweh/wxx108.

20. Wilson IG. Airborne campylobacter infection in a poultry worker: case report and review of the literature. Commun Dis Public Health. 2004;7:349-53 PMID: 15779805.

21. Letourneau V, Nehme B, Meriaux A, Massé D, Cormier $Y$, Duchaine $C$. Human pathogens and tetracycline-resistant bacteria in bioaerosols of swine confinement buildings and in nasal flora of hog producers. Int J Hyg Environ Health. 2010;213:444-9. https://doi.org/10.1016/j.ijheh.2010.09.008.

22. Gadde U, Kim WH, Oh ST, Lillehoj HS. Alternatives to antibiotics for maximizing growth performance and feed efficiency in poultry: a review. Anim Health Res Rev. 2017;18(1):26-45. https://doi.org/10.1017/ S1466252316000207.

23. Gadde UD, Oh S, Lillehoj HS, Lillehoj EP. Antibiotic growth promoters virginiamycin and bacitracin methylene disalicylate alter the chicken intestinal metabolome. Sci Rep. 2018;8:3592. https://doi.org/10.1038/s41598018-22004-6.

24. Dumonceaux TJ, Hill JE, Hemmingsen SM, Van Kessel AG. Characterization of intestinal microbiota and response to dietary virginiamycin supplementation in the broiler chicken. Appl Environ Microbiol. 2006;72: 2815-23. https://doi.org/10.1128/AEM.72.4.2815-2823.2006.

25. Angelakis E. Weight gain by gut microbiota manipulation in productive animals. Microb Pathog. 2017;106:162-70. https://doi.org/10.1016/j.micpath. 2016.11.002.

26. Serhan CN. Resolution phases of inflammation: novel endogenous antiinflammatory and proresolving lipid mediators and pathways. Annu Rev Immunol. 2007;25:101-37. https://doi.org/10.1146/annurev.immunol.25. 022106.141647

27. Buret AG. Immuno-modulation and anti-inflammatory benefits of antibiotics: the example of tilmicosin. Can J Vet Res. 2010;74:1-10 PMID: 20357951.

28. Belizario JE, Napolitano M. Microbiomes and their roles in dysbiosis, common diseases and novel therapeutic approaches. Front Microbiol. 2015; 6:1050. https://doi.org/10.3389/fmicb.2015.01050.

29. Turnbaugh PJ, Ley RE, Mahowald MA, Magrini V, Mardis ER, Gordon J. An obesity-associated gut microbiome with increased capacity for energy harvest. Nature. 2006;444:1027-31. https://doi.org/10.1038/nature05414.

30. Turnbaugh PJ, Hamady M, Yatsunenko T, Duncan A, Ley RE, Sogin ML, et al. A core gut microbiome in obese and lean twins. Nature. 2008;457(7228): 480-4. https://doi.org/10.1038/nature07540.

31. Le Roy CIL, Beaumont M, Jackson MA, Steves CJ, Spector TD, Bell JT. Heritable components of the human fecal microbiome are associated with visceral fat. Gut Microbes. 2018;9(1):61-7. https://doi.org/10.1080/19490976.2017.

32. Cani PD, de Vos WM. Next-generation beneficial microbes: the case of Akkermansia muciniphila. Front Microbiol. 2018;8:1765. https://doi.org/10. 3389/fmicb.2017.01765.

33. Belizário JE, Faintuch J, Garay-Malpartida M. Gut microbiome dysbiosis and immunometabolism: new frontiers for treatment of metabolic diseases. Mediators Inflamm. 2018;2018:2037838. https://doi.org/10.1155/2018/ 2037838.

34. Revolledo L, Ferreira CS, Ferreira AJ. Prevention of salmonella Typhimurium colonization and organ invasion by combination treatment in broiler chicks. Poult Sci. 2009;88:734-43. https://doi.org/10.3382/ps.2008-00410.

35. Kerr AK, Farrar AM, Waddell LA, Wilkins W, Wilhelm BJ, Bucher O, et al. A systematic review-meta-analysis and meta-regression on the effect of selected competitive exclusion products on salmonella spp. prevalence and concentration in broiler chickens. Prev Vet Med. 2013;111(1-2):112-225. https://doi.org/10.1016/j.prevetmed.2013.04.005.

36. Ceccarelli D, van Essen-Zandbergen A, Smid B, Veldman KT, Boender GJ, Fischer EAJ, et al. Competitive exclusion reduces transmission and excretion of extended-spectrum- $\beta$-lactamase-producing Escherichia coli in broilers. Appl Environ Microbiol. 2017;83(11). https://doi.org/10.1128/AEM.03439-16.

37. Nakamura A, Ota Y, Mizukami A, Ito T, Ngwai YB, Adachil Y. Evaluation of aviguard, a commercial competitive exclusion product for efficacy and aftereffect on the antibody response of chicks to salmonella. Poult Sci. 2002;81: 1653-60. https://doi.org/10.1093/ps/81.11.1653.

38. Bober JR, Beisel CL, Nair NU. Synthetic biology approaches to engineer probiotics and members of the human microbiota for biomedical applications. Annu Rev Biomed Eng. 2018;20:277-300. https://doi.org/10. 1146/annurev-bioeng-062117-121019.

39. de Vos WM, de Vos EAJ. Role of the intestinal microbiome in health and disease: from correlation to causation. Nutr Rev. 2012;70:545-56. https://doi. org/10.1111/j.1753-4887.2012.00505.x.

40. Lebeer S, Bron PA, Marco ML, van Pijkeren J-T, Motherway MO, Hill C, et al. Identification of probiotic effector molecules: present state and future perspectives. Curr Opin Biotechnol. 2018;49:217-23. https://doi.org/10.1016/ j.copbio.2017.10.007.

41. Zhang ZF, Kim H. Effects of multistrain probiotics on growth performance, apparent ileal nutrient digestibility, blood characteristics, cecal microbial shedding, and excreta odor contents in broilers. Poult Sci. 2014;93:364-70. https://doi.org/10.3382/ps.2013-03314.

42. Bai SP, Wu AM, Ding XM, Lei Y, Bai J, Zhang KY, et al. Effects of probioticsupplemented diets on growth performance and intestinal immune characteristics of broiler chickens. Poult Sci. 2013;92:663-70. https://doi.org/ 10.3382/ps.2012-02813.

43. Bron PA, Kleerebezem M. Lactic acid bacteria for delivery of endogenous or engineered therapeutic molecules. Front Microbiol. 2018;9:1821. https://doi. org/10.3389/fmicb.2018.01821.

44. LeCureux JS, Dean GA. Lactobacillus mucosal vaccine vectors: immune responses against bacterial and viral antigens. mSphere. 2018;3(3). https:// doi.org/10.1128/mSphere.00061-18. 
45. Roto SM, Rubinelli PM, Ricke SC. An introduction to the avian gut microbiota and the effects of yeast-based prebiotic-type compounds as potential feed additives. Front Vet Sci. 2015;2:28. https://doi.org/10.3389/ fvets.2015.00028

46. Czerucka D, Piche T, Rampal P. Review article: yeast as probiotics -saccharomyces boulardii. Aliment Pharmacol Ther. 2007;26(6):767-78. https://doi.org/10.1111/j.1365-2036.2007.03442.x.

47. Kaper JB, Nataro JP, Mobley HLT. Pathogenic Escherichia coli. Nat Rev Microbiol. 2004;2:123-40. https://doi.org/10.1038/nrmicro818.

48. Rojas-Lopez M, Monterio R, Pizza M, Desvaux M, Rosini R. Intestinal pathogenic Escherichia coli: insights for vaccine development. Front Microbiol. 2018;9:440. https://doi.org/10.3389/fmicb.2018.00440.

49. Fallavena LC, Moraes $H L$, Salle $C T$, Silva AB, Vargas RS, Nascimento VP, et al. Diagnosis of skin lesions in condemned or downgraded broiler carcasses a microscopic and macroscopic study. Avian Pathol. 2000;29:557-62. https:// doi.org/10.1080/03079450020016797.

50. Guabiraba R, Schouler C. Avian colibacillosis: still many black holes. FEMS Microbiol Lett. 2015;362(15):fnv118. https://doi.org/10.1093/femsle/fnv11.

51. Silveira F, Maluta RP, Tiba MR, Paiva JB, Guastalli EAL, Siveira WD. Comparison between avian pathogenic (APEC) and avian faecal (AFEC) Escherichia coli isolated from different regions in Brazil. Vet J. 2016;217:65-7. https://doi.org/10.1016/j.tvjl.2016.06.007.

52. Ferreira JC, Penha-Filho RAC, Kuaye APY, Andrade LN, Chang Y-C, Darini ALC. Virulence potential of commensal multidrug resistant Escherichia coli isolated from poultry in Brazil. Infec Gent Evol. 2018;65:251-6. https://doi. org/10.1016/j.meegid.2018.07.037.

53. Maciel JF, Matter LB, Trindade MM, Camillo G, Lovato M, Botton AS, Vargas AC. Virulence factors and antimicrobial susceptibility profile of extraintestinal Escherichia coli isolated from an avian colisepticemia outbreak. Microb Pathog. 2016;103:119-22. https://doi.org/. https://doi.org/10.1099/jmm.0. 000937

54. Bergeron CR, Prussing C, Boerlin P, Daignault D, Dutil L, Reid-Smith RJ, et al. Chicken as reservoir for extraintestinal pathogenic Escherichia coli in humans. Emerg Infect Dis (Canada). 2012;18:415-21. https://doi.org/10.3201/ eid1803.111099.

55. Ewers C, Li G, Wilking H, Kiebling S, Alt K, Antao E, et al. Avian pathogenic, uropathogenic, and newborn meningitis-causing Escherichia coli: how closely related are they? Int J Med Microbiol. 2007;297:163-76. https://doi. org/10.1016/j.jijmm.2007.01.003.

56. Yaguchi K, Ogitani T, Osawa R, Kawano M, Kokumai N, Kaneshige T, et al. Virulence factors of avian pathogenic Escherichia coli strains isolated from chickens with colisepticemia in Japan. Avian Dis. 2007;51:656-62. https://doi. org/10.1637/0005-2086(2007)51[656:VFOAPE]2.0.CO;2.

57. De Carli S, Ikuta N, Lehmann FK, da Silveira VP, de Melo Predebon G, Fonseca AS, et al. Virulence gene content in Escherichia coli isolates from poultry flocks with clinical signs of colibacillosis in Brazil. Poult Sci. 2015; 94(11):2635-40. https://doi.org/10.3382/ps/pev256.

58. Johnson TJ, Wannemuehler Y, Johnson SJ, Stell AL, Doetkot C, et al. Comparison of extraintestinal pathogenic Escherichia coli strains from human and avian sources reveals a mixed subset representing potential zoonotic pathogens. Appl Envirom Microbiol. 2008;74(22):7043-50. https:// doi.org/10.1128/AEM.01395-08.

59. Nakazato G, Gyles C, Ziebell K, Keller R, Trabulsi LR, Gomes TA, et al Attaching and effacing Escherichia coli isolated from dogs in Brazil: characteristics and serotypic relationship to human enteropathogenic E. coli (EPEC). Vet Microbiol. 2004;101(4):269-77. https://doi.org/10.1016/j.vetmic. 2004.04.009.

60. de Pace F, Nakazato G, Pacheco A, Boldrin de Paiva J, Sperandio V, Dias da Silveira $\mathrm{W}$. The type VI secretion system plays a role in type 1 fimbria expression and pathogenesis of an avian pathogenic Escherichia coli strain. Infect Immun. 2010;78:4990-8. https://doi.org/10.1128/IAl.00531-10.

61. Paiva JB, Mendes-da-Silva LP, Tiba MRC, Conceicao RA, Nakazato G, Pace F, et al. In vivo influence of in vitro up-regulated genes in the virulence of an APEC strain associated with swollen head syndrome. Avian Pathol. 2016; 45(1):94-105. https://doi.org/10.1080/03079457.2015.1125995.

62. Kariyawasam S, Wilkie BN, Gyles CL. Construction, characterization, and evaluation of the vaccine potential of three genetically defined mutants of avian pathogenic Escherichia coli. Avian Dis. 2004;48:287-99. https://doi.org/ $10.1637 / 7093$

63. Ghunaim H, Abu-Madi MA, Kariyawasam S. Advances in vaccination against avian pathogenic Escherichia coli respiratory disease: potentials and limitations. Vet Microbiol. 2014;172(1-2):13-22. https://doi.org/10.1016/j. vetmic.2014.04.019.

64. Fernandes-Filho T, Favaro-Jr C, Ingberman M, Beirao BCB, Inoue S, Gomes L, et al. Effect of spray Escherichia coli vaccine on the immunity of poultry. Avian Dis. 2013;57:671-6. https://doi.org/10.1637/10456-112612-ResNote.1.

65. Sadeyen J-R, Wu Z, Davies H, Diemen PM, Milicic A, La Ragione RM, et al. Immune responses associated with homologous protection conferred by commercial vaccines for control of avian pathogenic Escherichia coli in turkeys. Vet Res. 2015;46:5. https://doi.org/10.1186/s13567-014-0132-5.

66. Sperandio V, Mellies JL, Nguyen W, Shin S, Kaper JB. Quorum sensing controls expression of the type III secretion gene transcription and protein secretion in enterohemorrhagic and enteropathogenic Escherichia coli. Proc Natl Acad Sci U S A. 1999;96(26):15196-201. https://doi.org/10.1073/pnas.96.26.15196.

67. Han X, Bai H, Tu J, Yang L, Xu D, Wang S, et al. Deletion of luxS further attenuates the virulence of the avian pathogenic Escherichia coli aroA mutant Microb Pathog. 2015;88:39-47. https://doi.org/10.1016/j.micpath.2015.08.003.

68. Boots AW, van Berkel JJ, Dallinga JW, Smolinska A, Wouters EF, et al. The versatile use of exhaled volatile organic compounds in human health and disease. J Breath Res. 2012;6:027108. https://doi.org/10.1088/1752-7155/6/2/ 027108.

69. Lemfack MC, Gohlke BO, Toguem SMT, Preissner S, Piechulla B, Preissner R. mVOC 2.0: a database of microbial volatiles. Nucleic Acids Res. 2018;46(D1): D1261-5. https://doi.org/10.1093/nar/gkx1016.

70. Bos LD, Sterk PJ, Schultz MJ. Volatile metabolites of pathogens: a systematic review. PLoS Pathog. 2013;9(5):e1003311. https://doi.org/10.1371/journal. ppat.1003311.

71. Audrain B, Farag MA, Ryu C-M, Ghigo J-M. Role of bacterial volatile compounds in bacterial biology. FEMS Microbiol Rev. 2015;39(2):222-33. https://doi.org/10.1093/femsre/fuu013.

72. Amann A, Costello Bde L, Miekisch W, Schubert J, Buszewski B, Pleil J, et al. The human volatilome: volatile organic compounds (VOCs) in exhaled breath, skin emanations, urine, feces and saliva. J Breath Res. 2014:8:034001. https://doi.org/10.1088/1752-7155/8/3/034001

73. Lawal O, Knobel H, Weda H, Nijsen TME, Goodacre R, Fowler SJ, et al. TD/ GC-MS analysis of volatile markers emitted from mono- and co-cultures of Enterobacter cloacae and Pseudomonas aeruginosa in artificial sputum. Metabolomics. 2018;14:66. https://doi.org/10.1007/s11306-018-1357-5.

74. Palma SICJ, Traguedo AP, Porteira AR, Frias MJ, Gamboa H, Roque ACA. Machine learning for the meta analyses of microbial pathogens' volatile signatures. Sci Rep. 2018;8:3360. https://doi.org/10.1038/s41598-018-21544-1.

75. Laor Y, Koziel JA, Cai L, Ravid U. Chemical-sensory characterization of dairy manure odor using headspace solid-phase microextraction and multidimensional gas chromatography mass spectrometry-olfactometry. J Air Waste Manag Assoc. 2008;58(9):1187-97. https://doi.org/doi. https://doi. org/10.3155/1047-3289.58.9.1187

76. Lonsdale CL, Taba C, Queralto C, Lukaszewski RA, Martino RA, Rhodes PA, et al. The use of colorimetric sensor arrays to discriminate between pathogenic bacteria. PLoS One. 2013;8(5):e62726. https://doi.org/10.1371/ journal.pone.0062726.

77. Wilson AD. Advances in electronic-nose technologies for the detection of volatile biomarker metabolites in the human breath. Metabolites. 2015:5: 140-63. https://doi.org/10.3390/metabo5010140.

78. Pang $X, N a n ~ H$, Zhong J, Ye D, Shaw MD, Lewis AC. Low-cost photoionization sensors as detectors in GC $\times$ GC systems designed for ambient VOC measurements. Sci Total Environ. 2019;664:771-9. https://doi. org/10.1016/j.scitotenv.2019.01.348.

79. Aguilar PS, de Mendoza D. Control of fatty acid desaturation: a mechanism conserved from bacteria to humans. Mol Microbiol. 2006;62(6):1507-14. https://doi.org/10.1111/j.1365-2958.2006.05484.x.

80. Kunitsky C, Osterhout G, Sasser M. Identification of microorganisms using fatty acid methyl ester (FAME) analysis and the MIDI Sherlock microbial identification system. In: Miller MJ, editor. Encyclopedia of rapid microbiological methods, vol. 3. River Grove: DHI Publishing, LLC; 2006. p. 1-18.

81. Dawyndt $P$, Vancanneyt M, Snauwaert C, De Baets B, De Meyer H, Swings J. Mining fatty acid databases for detection of novel compounds in aerobic bacteria. J Microbiol Methods. 2006;66(3):410-33. https://doi.org/10.1016/j. mimet.2006.01.008.

82. Härtig C. Rapid identification of fatty acid methyl esters using a multidimensional gas chromatography-mass spectrometry database. J Chromatogr A. 2008;1177(1):159-69. https://doi.org/10.1016/j.chroma.2007. 10.089 
83. Tait E, Perry JD, Stanforth SP, Dean JR. Identification of volatile organic compounds produced by bacteria using HS-SPME-GC-MS. J Chromatogr Sci. 2014;52(4):363-73. https://doi.org/10.1111/jam.12418.

84. Hopkins MJ, Sharp R, Macfarlane GT. Age and disease related changes in intestinal bacterial populations assessed by cell culture, 16S rRNA abundance, and community cellular fatty acid profiles. Gut. 2001;48:198205. https://doi.org/10.1136/gut.48.2.198

85. Roth SR, Henkel K, Altenburger MJ, Auwärter V, Neukamm MA. Multivariate optimization of a method for the determination of fatty acids in dental biofilm by GC-MS. Bioanalysis. 2018;10(16):1319-33. https://doi.org/10.4155/ bio-2018-0106

86. Slabbinck B, Waegeman W, Dawyndt P, De Vos P, De Baets B. From learning taxonomies to phylogenetic learning: integration of $16 \mathrm{~S}$ rRNA gene data into FAME-based bacterial classification. BMC Bioinformatics. 2018;11:69. https://doi.org/10.1186/1471-2105-11-69.

87. Dyar OJ, Huttner B, Schouten J, Pulcini C, ESGAP (ESCMID study Group for Antimicrobial stewardship). What is antimicrobial stewardship? Clin Microbiol Infect. 2017;23(11):793-8. https://doi.org/10.1016/j.cmi.2017.08.026.

88. Crofts TS, Gasparrini AJ, Dantas G. Next-generation approaches to understand and combat the antibiotic resistome. Nat Rev Microbiol. 2017; 15:422-34. https://doi.org/10.1038/nrmicro.2017.

89. Buckner MMC, Ciusa ML, Piddock LJV. Strategies to combat antimicrobia resistance: anti-plasmid and plasmid curing. FEMS Microbiol Rev. 2018;42(6): 781-804. https://doi.org/10.1093/femsre/fuy031.

\section{Publisher's Note}

Springer Nature remains neutral with regard to jurisdictional claims in published maps and institutional affiliations.

Ready to submit your research? Choose BMC and benefit from:

- fast, convenient online submission

- thorough peer review by experienced researchers in your field

- rapid publication on acceptance

- support for research data, including large and complex data types

- gold Open Access which fosters wider collaboration and increased citations

- maximum visibility for your research: over $100 \mathrm{M}$ website views per year

At $\mathrm{BMC}$, research is always in progress.

Learn more biomedcentral.com/submissions 